\title{
Pelatihan Wasit Tenis Lisensi Daerah Riau 2019
}

\author{
${ }^{1}$ Rezki, ${ }^{2}$ Rices Jatra, ${ }^{3}$ Sesi Melati \\ Universitas Islam Riau \\ rezki@edu.uir.ac.id ${ }^{1}, \underline{\text { ricesjatra@edu.uir.ac.id }}{ }^{2}$, sesimelati@gmail.com $^{3}$
}

Diterima: 27 Mei 2020; Revisi: 28 Mei 2020; Disetujui: 29 Mei 2020

\begin{abstract}
Abstrak
Perkembangan turnamen tenis lapangan beberapa tahun terakhir ini sangat menunjukan peningkatan yang signifikan. Hal ini terlihat dengan makain banyaknya kejuaraan tenis baik itu tingkat daerah Nasional maupun turnamen Veteran. Maka dari itu sangat dibutuhakn tenaga yang profesional untuk menjadi seorang wasit dalam memimpin pertandingan. Untu menjadi wasit perlu adanya pelatihan atau Penataran. Kegiatan meliputi "Pelatihan Wasit Tenis Tingkat Daerah Riau 2019”. Kegiatan ini dilaksanakan di Bangkinang Kabupaten Kampar dengan hasil yang sangat baik. Peserta mendapatkan ilmu yang bermanfaat serta lisensi sebagai wasit tenis lisensi daerah bagi yang lulus. Sehingga mereka bias enjadikan karir wasitb tenis sebagai penghasilan sampingan.
\end{abstract}

Kata Kunci: Pelatihan Wasit Tenis Tingkat Daerah

\section{Abstract}

The development of field tenis tournaments in recent yearshas shown a significant increase. This can be seen fromthe fact that there are lot of tenis championships bot at the national level nad the veteranstournament. There fore it is very necessary profesional staff to become a referee, training or upgrading is needed. Activities include "Riau Regional Tenis Referee Training 2019”. This activity was held in Bangkinang, Kampar District with very good results. Participants gain useful knowledge and a license as a regional tenis referee for those who graduate. So they can make the referee career a secondary income.

Keywords : Regional Tennis Referee Training

\section{ANALISIS SITUASI}

Tenis Lapangan adalah salah satu cabang olahraga yang sudah mulai digemari oleh banyak kalangan di Indonesia. Hal ini terlihat banyaknya orang yang bermain tenis mulai dari anak anak sampai veteran. Dilihat dari pertandingan, turnament tenis lapangan mulai dari tingkat kelompok umur sampai kelompok veteran. Dalam buku Peraturan Turnamen diakui PELTI kelompok umum tahun 2018 menyebutkan 'Pertumbuhan dan perkembangan tenis nasional dewasa ini telah menunjukan tingkat kemajuan cukup berarti, perlu terus dijaga dan ditumbuhkembangkan lebih lanjut sehingga mampu berbicara secara lebih mantap dipercaturan tenis international. Untuk itu perlu dukungan sepenuhnya dari setiap perangkat organisasi agar prestasi menyeluruh dari para pemain, official, dan penyelenggara setiap turnament mampu mencapai sasaran yang telah ditetapkan.

Menurut (Nelistya, 2011) wasit (umpire) adalah orang yang bertanggung jawab atas berlangsungnya pertandingan dengan adil. Wasit tenis merupakan pemimpin pertandingan 
yang bertugas dan bertanggung jawab terhadap jalannya pertandingan. Parry (2008:3) mengungkapkan bahwa "Two main duties of tennis chair umpire are to control the match and communicate what is going on in match to spectator". Berdasarkan ungkapan tersebut maka tugas pokok wasit tenis adalah mengontrol jalannya pertandingan berdasarkan prosedur dan peraturan tenis serta mengkomunikasikan apa yang terjadi dalam pertandingan seperti bola masuk atau keluar kepada pemain dan penonton. Pengurus Pusat Persatuan Lawn Tenis Indonesia (PP PELTI) mengkategorikan tingkatan wasit tenis berdasarkan sertifikat yaitu tingkat daerah (Pengcab), tingkat provinsi (Pengprov) dan tingkat nasional. Tingkatan tersebut membedakan kemampuan yang dimiliki oleh wasit yang bersangkutan dan sebagai syarat untuk dapat bertugas di level turnamen tertentu seperti untuk dapat bertugas di turnamen tingkat nasional maka seorang wasit harus memiliki sertifikat wasit tenis tingkat nasional.. Dalam hal ini kami nekerja sama dengan PELTI Kabupaten Kampar berusaha untuk berpartisifasi dalam meningkatkan sumberdaya manusia dalam bidang tenis yaitu wasit tenis lapangan serta melakukan pengembangan dalam cabang olahraga tenis melalui "Pelatihan Wasit Tenis Lapangan Lisensi Daerah Riau Tahun 2019”

\section{SOLUSI DAN TARGET}

Adapun solusi dan target yang ingin dicapai dalam pelaksanaan pelatihan wasit lisensi daerah yang dilaksanakan di bangkinang adalah pemuda setempat, atlet yang sudah tidak produktif lagi dan mahaisiwa olahraga yang berasal dari berbagai Universitas di Riau maupun dari luar Riau. Dengan adanya pelatihan ini akan tercapai target menghasilkan wasit tenis yang mampu mewasiti pertandingan tenis lapangan di berbagai event baik event daerah maupun nasional.

\section{METODE PELAKSANAAN}

Program kegiatan yang akan di laksanakan berupa pelatihan wasit tenis tingkat

daerah Riau 2019 di lapangan tenis bangkinang Kampar Riau, dengan jumlah peserta sebanyak 25 orrang. Peserta adalah merupakan seluruh masyarakat yang mendaftar mengikuti pelatihan yang berasal dari pemuda setempat, para atlet yang sudah tidak aktif lagi dengan pertandingan dan dari kalangan mahasiswa yang berasal dari Univeersitas di Riau dan dari lauar Riau. Adapun lokasi pelaksanaan kegitan pelatihan wasit tenis lapangan ini adalah di Pelti Kabupaten kampar dan lapangan tenis Bangkinang Kab Kampar Riau.

\section{Metode Pelaksanaan}

\begin{tabular}{|c|c|c|c|c|}
\hline Hari/ Tanggal & Waktu & Jenis kegiatan & tempat & $\begin{array}{c}\text { Penanggung } \\
\text { jawab }\end{array}$ \\
\hline & $\begin{array}{c}\text { Senin } 08-00 \mathrm{sd} \\
12.00\end{array}$ & $\begin{array}{c}\text { Aturan } \\
\text { Permainan Tenis }\end{array}$ & Ruangan & \\
\hline & $12.00-13.30$ & ISHOMA & & \\
\hline & $13.00-18.00$ & $\begin{array}{c}\text { Kode etik wasit } \\
\text { tenis dan } \\
\text { prosedur } \\
\text { mewasiti }\end{array}$ & Ruangan & Rezki, Rices \\
\hline Selasa & $08.00-12.00$ & Praktek wasit & Lapangan & Rices, Daharis \\
\hline
\end{tabular}




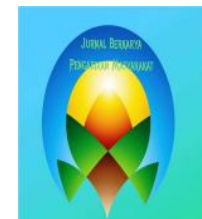

Journal Berkarya

Pengabdian kepada Masyarakat

Vol. 2, No. 1, Mei, 2020,

E - ISSN 2686-6218

\begin{tabular}{|l|c|c|c|c|}
\hline & & tenis & & \\
\hline & $12,00-13.30$ & ISHOMA & & \\
\hline & $13.30-15.30$ & Praktek & lapangan & Rices \\
\hline & $16.00-18.00$ & $\begin{array}{c}\text { Evalusai dan } \\
\text { ujian } \\
\text { Pemahaman }\end{array}$ & & Rices, Sesi \\
\hline
\end{tabular}

\section{PELAKSANAAN KEGIATAN}

\section{Dokumentasi Kegiatan dan Pengabdian}

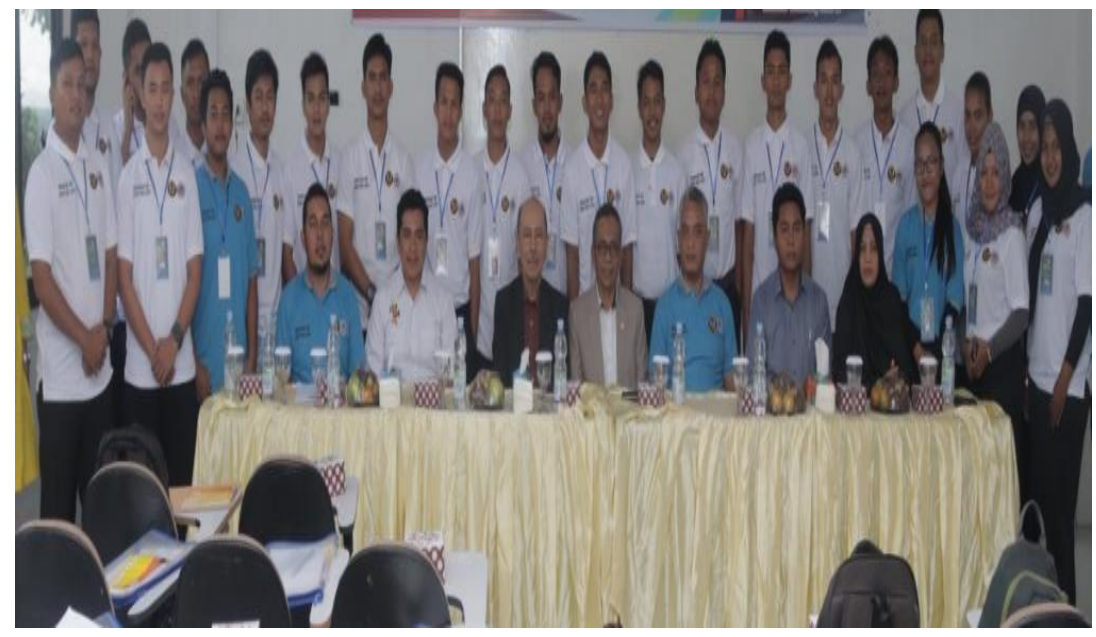

Gambar 1. Dokumentasi bersama peserta, panitia dan pengurus Pelti Kab kampar

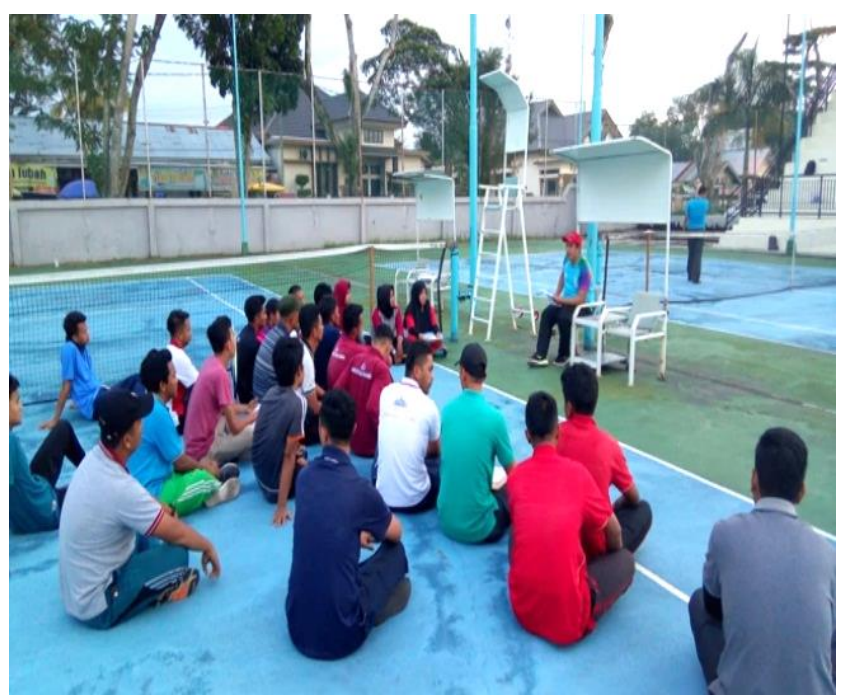

Gambar 2: Penyampaian materi tentang Peraturan permaianan Tenis Lapangan Oleh Rices Jatra, M.Pd ( Wasit tenis Lisensi Pre Level 2 ITF) dan Dupri, M.Pd Mental Seorang Wasit. 


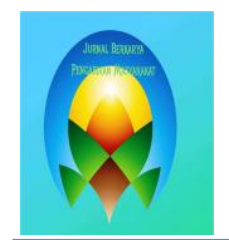

Journal Berkarya

Pengabdian kepada Masyarakat

Vol. 2, No. 1, Mei, 2020,

E - ISSN 2686-6218

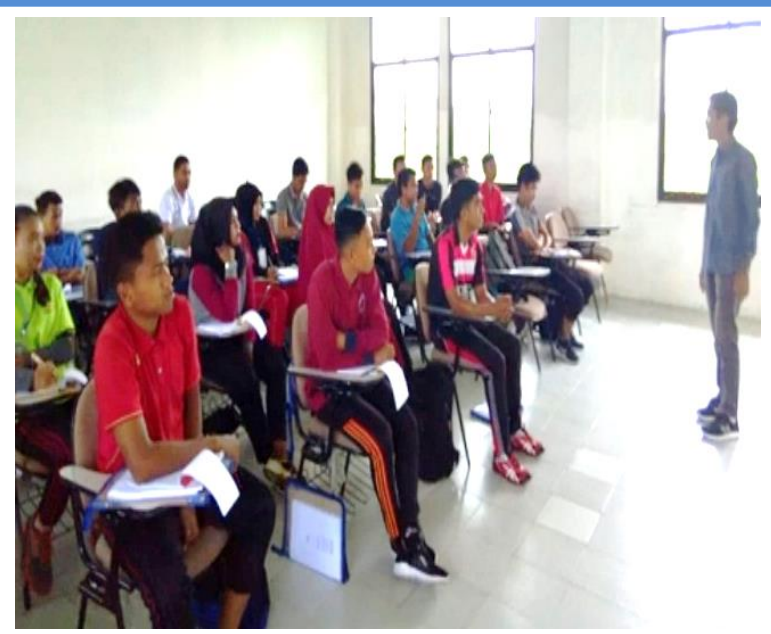

Gambar 3. Kode Etik Wasit Tenis

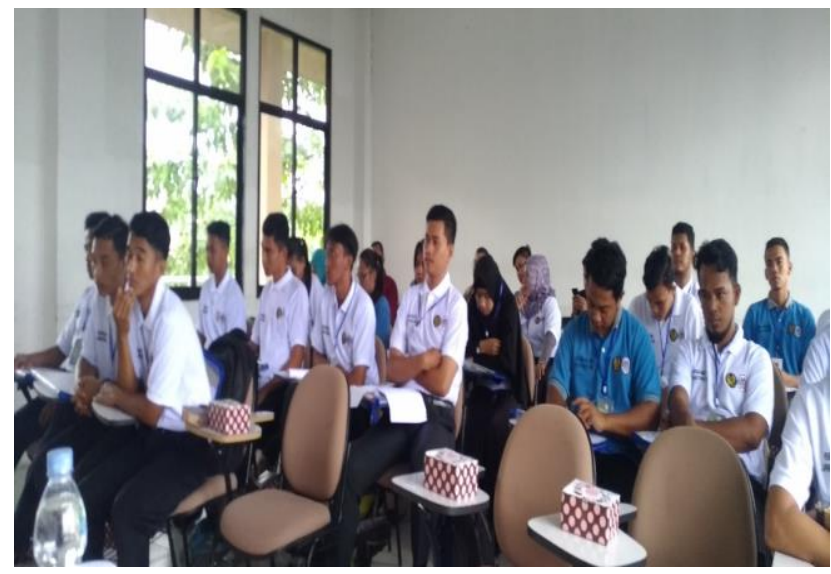

Gambar 4. Prosedur Mewasiti

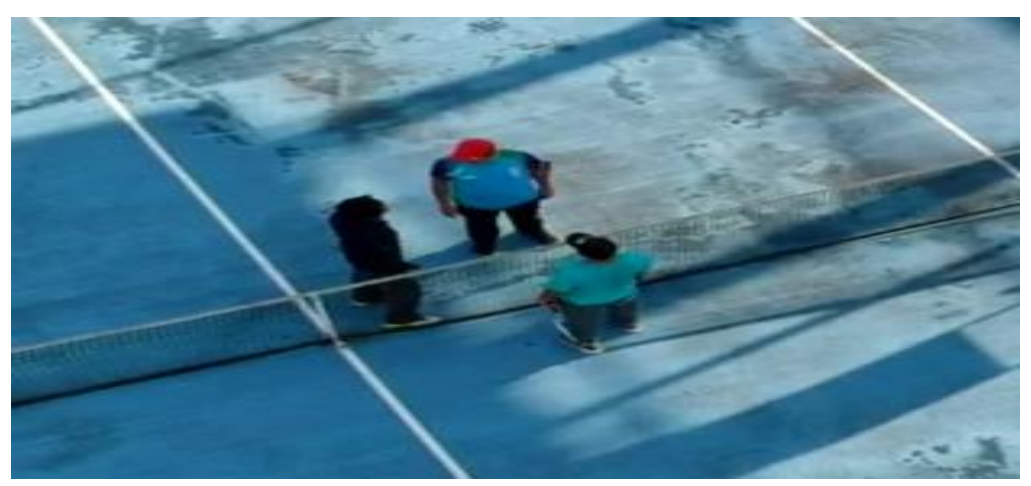

Gambar 3: Pelaksanaan Praktek Wasit

\section{HASIL DAN PEMBAHASAN}

Pelatihan wasit tenis lisensi daerah diawali dengan pembukaan dan penyajian teori mengenai pemahaman peraturan permainan tenis serta pemahaman mengenai tata cara dalam melakukan hal hal yang berhubungan dengan wasit bdi lapangan. Pada hari berikutnya pagi 
menyambung penjelasan teori peraturan permainan tenis lapangan dan siang sampai sore peserta melakukan praktek wasit dilapangan.

Berdasarkan hasil pengamatan selama kegiatan Pengabdian berlangsung diperoleh hasil yang positif diantaranya sebagai berikut: 1) Para peserta melakukan dengan disipilin dan penuh konsentrasi. 2) Para peserta aktif bertanya, serta melakukan praktek dengan seksama bersama pemateri atau instruktur. Kegiatan ini memberikan sumbangan positif kepada peserta dimana peserta yabng lulus mengikuti pelatihan mendapatkan kesempatan untuk bisa mewasiti di tingkat daerah.

Menurut (Rubeni, 2012) tugas pokok wasit adalah mengontrol jalannya pertandingan berdasarkan prosedur dan peraturan tenis serta mengkomunikasikan apapun yang terjadi dalam pertandingan seperti bola masuk dan bola keluar kepada pemain dan penonton. Peserta ingin meningkatkan kemampuannya dalam perwasitan tenis lapangan. Diakhir pelaksanaan peserta berpesan untuk diadakan pelatihan tingkat nasional.

Sehingga mereka mampu nantinya bisa melanjutkan ketingkat yang lebih tinggi dan bisa mewasiti di turnamen nasional maupun international. Pelatihan ini memberikan masukan apda wasit, sehinggawasit bisa lebih bertanggung jawab dengan tugasnya diantaranya sebagai berikut.: a) Melakukan calls lines ketika wasit garis tidak ditugaskan b) Menugaskan wasit garis; c) Memberikan instruksi pemain di lapangan; d) Menyebutkan skor; e) Mengamati perpindahan tempat pemain; f) Menulis skor g) Pengskoran pertandingan h) Membuat keputusan dalam kesalahan yang terjadi i) Menentukan hukuman pada pemain yang melanggar j) Calls pengulangan servis maupun pertandingan; k) Calls foot faults l) Calls service lets $\mathrm{m}$ ) Memberikan tanda dan pemberitahuan saat bola menyentuh batas garis lapangan) Melakukan calls pada berbagai macam pelanggaran.

Menurut (Hadi, 2018) bahwa seorang wasit yang sukses dilapangan adalah wasit yang mampu menjadikan pertandingan itu berjalan dengan aman dan lancar tampa ada protes dari pemain. Wasit adalah seorang yang memiliki wewenang untuk mengatur jalannya suatu pertandingan olahraga. Namun seorang wasit harus memiliki keyakinan dan berkonsentrasi dalam memimpin pertandingan, supaya pertandingan berjalan dengan lancar. Sebagaimana dikatakan oleh (Sukadiyanto, 2005) bahwa tingkat kemampuan konsentrasi dan kecermatan para wasit inilah yang seringkali menghasilkan keputusan yang kontroversi dengan kondisi sesungguhnya.

\section{KESIMPULAN}

Wasit merupakan pengadil dalam permainan tenis lapanghan. Untuk menjadi seorang wasit tenis harus memiliki mengikuti penataran wasit lisensi daerah. Dan setelah itu bisa mengikuti menjadi seorang wasit di lapangan tenis.

\section{SARAN}

1. Bagi peserta agar dapat memperkaya pengalamannya dengan melatih menjadi wasit saat ada pertandingan maupun latihan tenis dilapangan tenis

2. Bagi peserta harus mengetahui aturan permainan tenis dengan baik

3. Dengan penguasaan aturan permainan yang baik maka seorang wasit akan mampu memimpin pertandingan dengan baik pula untuk itu setiap tahunnya harus diadakan penyegaran wasit

4. Bagi Pengda PELTI agar dapat meningkatkan karir wasit ke lisensi yang lebih tinggi. 
PENGAKUAN

Dalam kesempatan ini kami tim pengabdian kepada masyarakat tidak hentinya mengucapkan rasa syukur sebesar-besarnya kepada Allah SWT karena dengan rahmadnya jugalah kegiatan pengabdian kepada masyarakat ini berjalan dengan baik dan benar. Kami juga mengucapkan ucapan terimakasih kepada pihak Universitas Isalm riau dan pihak LPPM Universitas Islam Riau Ketua PELTI Provinsi Riau, KONI Kabupaten Kampar dan Ketua PELTI Kabupaten Kampar yang telah memberikan kesempatan kepada kami dalam melakukan kegiatn pengabdian kepada masyarakat. Kepada mahasiawa dan masyarakat sekitar yang telah banyak membatu dan mempermudah kami dalam memlukan kegiatan pengabdian kepada masyarakat.

\section{DAFTAR PUSTAKA}

Hadi, H. (2018). Pemahaman Peraturan Permainan Tenis Pada Peserta Penataran Wasit Tenis Di Universitas Pgri Semarang. Multilateral Jurnal Pendidikan Jasmani Dan Olahraga, 2(17), 98-102.

Jatra, R., \& Fernando, D. D. (2019). The understanding of court tennis rules for participants of licensing tennis umpire training. Jurnal SPORTIF: Jurnal Penelitian Pembelajaran, 5(1), 70-79.

Nelistya, A. (2011). Menjadi Juara Tenis Meja. Bogor.

Rubeni, Y. (2012). Hubungan Kualifikasi Pendidikan, Pengalaman dan Motivasi dengan Kinerja Wasit Tenis. Universitas Pendidikan Indonesia.

Sukadiyanto, S. (2005). Prinsip-Prinsip Pola Bermain Tenis Lapangan. JORPRES (Jurnal Olahraga Prestasi), 1(2). 